\title{
Interaction of Salivary alpha-Amylase and Amylase-Binding-Protein A (AbpA) of Streptococcus gordonii with Glucosyltransferase of $S$. gordonii and Streptococcus mutans
}

\author{
Biswendu Chaudhuri ${ }^{1}$, Jennifer Rojek ${ }^{1}, M$ Margaret Vickerman ${ }^{1,2}$, \\ Jason M Tanzer ${ }^{3}$ and Frank A Scannapieco*1
}

Address: ${ }^{1}$ Department of Oral Biology, School of Dental Medicine, State University of New York at Buffalo, New York, USA, ${ }^{2}$ Department of Periodontics and Endodontics, School of Dental Medicine, State University of New York at Buffalo, New York, USA and ${ }^{3}$ Department of Oral Health and Diagnostic Sciences, School of Dental Medicine, University of Connecticut Health Center, Connecticut, USA

Email: Biswendu Chaudhuri - bc28@buffalo.edu; Jennifer Rojek - jlrojek@buffalo.edu; M Margaret Vickerman - mmv4@buffalo.edu; Jason M Tanzer - Tanzer@NSO.UCHC.EDU; Frank A Scannapieco* - fas1@buffalo.edu

* Corresponding author

Published: 25 June 2007

BMC Microbiology 2007, 7:60 doi:10.1186/147/-2/80-7-60
Received: 27 October 2006

Accepted: 25 June 2007

This article is available from: http://www.biomedcentral.com/I47I-2/80/7/60

(c) 2007 Chaudhuri et al; licensee BioMed Central Ltd.

This is an Open Access article distributed under the terms of the Creative Commons Attribution License (http://creativecommons.org/licenses/by/2.0), which permits unrestricted use, distribution, and reproduction in any medium, provided the original work is properly cited.

\begin{abstract}
Background: Glucosyltransferases (Gtfs), enzymes that produce extracellular glucans from dietary sucrose, contribute to dental plaque formation by Streptococcus gordonii and Streptococcus mutans. The alpha-amylase-binding protein $\mathrm{A}(\mathrm{Abp} \mathrm{A})$ of $\mathrm{S}$. gordonii, an early colonizing bacterium in dental plaque, interacts with salivary amylase and may influence dental plaque formation by this organism. We examined the interaction of amylase and recombinant AbpA (rAbpA), together with Gtfs of S. gordonii and S. mutans.

Results: The addition of salivary alpha-amylase to culture supernatants of $S$. gordonii precipitated a protein complex containing amylase, AbpA, amylase-binding protein $B(A b p B)$, and the glucosyltransferase produced by $S$. gordonii (Gtf-G). rAbpA was expressed from an inducible plasmid, purified from Escherichia coli and characterized. Purified rAbpA, along with purified amylase, interacted with and precipitated Gtfs from culture supernatants of both $S$. gordonii and $S$. mutans. The presence of amylase and/or rAbpA increased both the sucrase and transferase component activities of $S$. mutans Gtf-B. Enzyme-linked immunosorbent assay (ELISA) using antiGtf-B antibody verified the interaction of rAbpA and amylase with Gtf-B. A S. gordonii abpAdeficient mutant showed greater biofilm growth under static conditions than wild-type in the presence of sucrose. Interestingly, biofilm formation by every strain was inhibited in the presence of saliva.
\end{abstract}

Conclusion: The results suggest that an extracellular protein network of AbpA-amylase-Gtf may influence the ecology of oral biofilms, likely during initial phases of colonization.

\section{Background}

Saliva-bacterial interactions influence the establishment and maintenance of the microflora of dental plaque [1-3].
Amylase is the most abundant enzyme in human saliva and is a constituent of the complex glycoproteinacious acquired pellicle that immediately forms on cleaned teeth 
[4-7]. Dental plaque forms on the pellicle and is responsible for the most common oral diseases, dental caries and periodontitis $[8,9]$. Amylase specifically binds with high affinity to several oral commensal streptococcal species, including Streptococcus gordonii, Streptococcus mitis, Streptococcus parasanguinis, Streptococcus cristatus, and Streptococcus salivarius, but not to Streptococcus sanguinis or to cariogenic streptococci including Streptococcus mutans and other mutans streptococci [10-13]. Amylase-binding bacteria constitute a substantial proportion of the total cultivable flora on human teeth and only colonize the mouths of animals with salivary amylase activity [14]. This suggests that the ability to bind amylase is ecologically advantageous to these bacteria for colonization of oral surfaces.

S. gordonii produces two amylase binding proteins: amylase binding protein A (AbpA) [15] and amylase binding protein $B(A b p B)[16]$. Both proteins are expressed transiently on the cell surface before release into the extracellular milieu in soluble form. AbpA is a $20 \mathrm{kDa}$ protein that acts as the major receptor for salivary amylase binding to the bacterial surface. Mutants deficient in AbpA adhere less well to amylase-coated hydroxyapatite and appear deficient in a dynamic model of biofilm formation in vitro [17]. Paradoxically, however, AbpA-deficient strains of $S$. gordonii colonize the mouths of conventional rats as well or better than do wild-type (WT) strains [18]. In fact, oral colonization by AbpA-deficient mutants appears augmented when the rats are fed dietary sucrose. Furthermore, glucosyltransferase (Gtf) activity, shown to be an important colonization factor for oral streptococci $[19,20]$, appears greater in AbpA-deficient mutants [18].

S. gordonii produces a single Gtf (Gtf-G) [21], while $S$. mutans produces three Gtfs (Gtf-B, Gtf-C, and Gtf-D) [22]. $\mathrm{Gtfs}$ synthesize extracellular glucan from sucrose and are long known as determinants of bacterial colonization of the teeth $[19,20]$. Gtf enzymatic action entails two steps: the hydrolysis of sucrose into fructose and glucose by its sucrase activity, and the transfer of glucosyl residues to form alpha-linked glucans by its transferase activity. Gtfs consist of two relatively conserved structural domains, an $\mathrm{N}$-terminal catalytic domain and a C-terminal glucanbinding domain [23]. Although Gtfs of $S$. gordonii and $S$. mutans have amino acid homologies within the conserved domains, the enzymes differ in their requirements for acceptor molecules and ability to produce glucans with varying proportions of $\alpha-1-3$ and $\alpha-1-6$ glucosidic linkages [22].

It has been reported that the interaction between amylase and streptococcal Gtf on saliva-coated hydroxyapatite surfaces results in reduction in Gtf enzymatic activity and glucan formation [24]. Thus, the interaction of these enzymes may modulate the adhesion and colonization of
S. gordonii and other Gtf-producing oral streptococci, e.g. $S$. mutans. Indeed, proteins released from one organism (e.g. S. gordonii) may interact with proteins released by another (S. mutans) within the oral biofilm milieu to modulate their function. The goal of this study therefore was to investigate the interaction of purified salivary amylase and rAbpA, alone and in combination, with Gtf of $S$. gordonii and S. mutans.

\section{Results \\ Precipitation of Gtf-G and AbpA from S. gordonii supernatants by salivary amylase}

Our previous studies revealed that the addition of purified amylase to $S$. gordonii culture supernatant resulted in the precipitation of soluble amylase-binding proteins [16]. To further investigate this interaction, purified amylase was added to cell-free culture supernatants of WT and mutant strains of $S$. gordonii. While addition of amylase did not induce precipitation of proteins from the AbpA- strain's culture supernatant, it did so from supernatants of both the AbpB- and WT strains (Fig. 1A; lanes 1, 2 and 3), indicating that AbpA is essential for precipitation. SDS-PAGE analysis of the precipitate from WT culture supernatant showed the presence of several proteins, including AbpA and $\mathrm{AbpB}$, as well as Gtf-G (Fig. 1A; lane 1). Precipitation of Gtf-G and other amylase-binding proteins by purified amylase was found to be dose-dependent; when amylase was added to $0,1,5,10,20,40,50 \mathrm{mg} / \mathrm{ml}$, maximum precipitation appeared to occur at $40 \mathrm{mg} / \mathrm{ml}$ and greater. A sham experiment in which buffer containing bovine serum albumin (BSA) alone was added in place of amylase did not precipitate any proteins (data not shown).

In contrast, SDS-PAGE analysis of 10-fold concentrated and dialyzed spent culture supernatant showed no protein bands above $20 \mathrm{kDa}$ on. Further, while amylase induced protein precipitation from cell free culture supernatants, it did not do so from dialyzed culture supernatant (data not shown). This observation suggested that ionic strength is also an important determinant for amylase induced precipitation.

Gtf-G activity assessment of precipitates from supernatants following addition of amylase revealed the essential lack of Gtf-G activity from the AbpA-strain (Fig. 1B; lane 2 ). The presence and absence of AbpA in the precipitate was verified by immuno-blotting using rabbit anti-AbpA antibody (Fig. 1C). MALDI-TOF analysis of proteins eluted from the gel identified $\mathrm{AbpB}$ and amylase in the precipitate obtained from WT culture supernatants. As shown in Fig. $1 \mathrm{~A}$ and $1 \mathrm{~B}$, while amylase did not precipitate Gtf-G from the AbpA- supernatant, it did so from supernatants of both the AbpB- strain and the WT. The presence of Gtf-G activity in the precipitates obtained from the supernatant of AbpA positive strains (WT and 


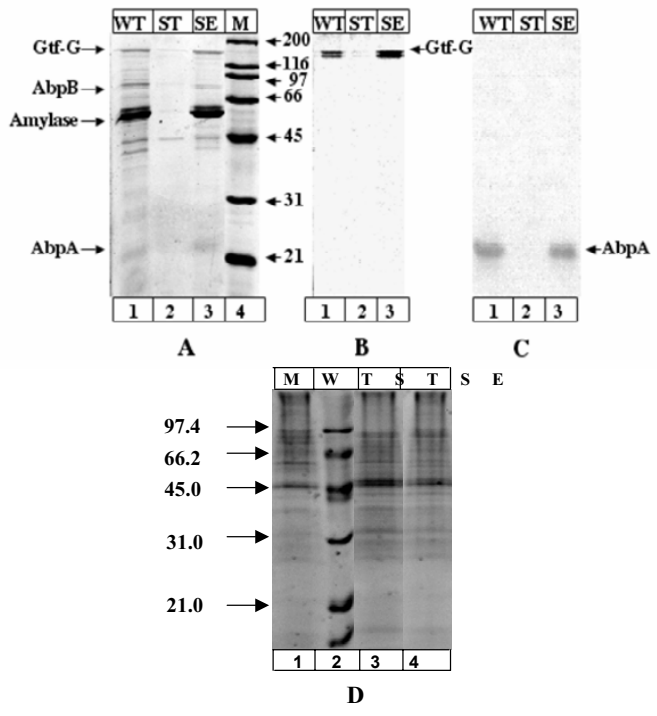

\section{Figure I}

SDS-PAGE analysis of amylase precipitates. Panel A. Precipitates from $18 \mathrm{~h}$ culture supernatants, were boiled in sample buffer. The samples containing $3.5 \mu \mathrm{g}$ of protein were run on $12 \%$ SDS-PAGE, followed by staining with SYPRO red in $7.5 \%$ acetic acid solution. Lane I, supernatant of wild type cells (WT); lane 2, supernatant of AbpA-deficient strain (ST); lane 3, supernatant of AbpB-deficient strain (SE); lane 4, molecular mass standard in kDa (M). Panel B. Precipitates from supernatants containing I.4 $\mu \mathrm{g}$ of protein were used for Gtf-G activity assay. Samples were run on a I2\% gel and stained for GTF activity. Lane I, supernatant from wild type culture (WT); lane 2, supernatant from AbpA-deficient cells (ST); lane 3, supernatant from AbpB-deficient cells (SE). Panel C. Precipitates from supernatants containing $1.4 \mathrm{mg}$ of total protein were used for Western Blot using polyclonal antiAbpA antibody. Lanel, 2, and 3, supernatants from wild type (WT), AbpA-deficient (ST), and AbpB-deficient cells (SE), respectively.

$\mathrm{AbpB}^{-}$mutant), and the absence of Gtf-G activity that could be harvested from the AbpA- supernatant, indicated that amylase together with AbpA interacted with and precipitated Gtf-G. Figure 1D shows an SDS-PAGE stained with SYPRO of alcohol precipitates from culture supernatants from each strain (WT, $\mathrm{AbpA}^{-}$and $\mathrm{AbpB}^{-}$). These precipitates show many more bands than found in the amylase precipitates from each strain, suggesting selective precipitation of only a few bands by amylase.

\section{Inhibition of (125I) $\alpha$-amylase-bacterium interactions by rAbpA}

Previous studies have shown that $\alpha$-amylase binds noncovalently to the $S$. gordonii surface with high affinity, and that AbpA acts as the major cell surface receptor for amylase binding $[10,15,17,25]$. To confirm the role of AbpA as this receptor, rAbpA was expressed and purified from $E$. coli as described in the Experimental Procedures section. Far western blot analysis of purified rAbpA using salivary amylase as a ligand confirmed the retention of its amylase binding activity. We further quantitatively measured binding of labeled amylase to the WT cell surface in the presence of purified rAbpA. The dose-dependent inhibition of $\left({ }^{125} \mathrm{I}\right)$-amylase to the bacterial surface following preincubation with $\mathrm{rAbpA}$ confirmed the amylase binding function of AbpA on the bacterial surface (data not shown).

\section{Amylase precipitates Gtf-G in the presence of rAbpA}

Because detectable levels of Gtf-G were not precipitated by amylase from the culture supernatant of the AbpA- (strain ST) strain (Fig. 1A and 1B), and amylase-binding proteins are not produced by $S$. mutans $[10,12,26]$, we used cellfree culture supernatants of the $\mathrm{AbpA}^{-}$strain of $S$. gordonii, and from S. mutans 10449S, for a Gtf-amylase precipitation assay in the presence or absence of exogenous purified rAbpA and/or amylase. Amylase, when added in the presence of rAbpA, precipitated Gtf-G from the AbpAstrain (strain ST) supernatant (Fig 2A) and rAbpA augmented amylase precipitation of Gtf-B, Gtf-C, and Gtf-D of $S$. mutans (Fig. 2B). However, amylase or rAbpA, singly, precipitated a small amount of GtfG and Gtf-C from the supernatants of these strains. As expected, the supernatant from a Gtf mutant of $S$. gordonii did not form any precipitate under any of these conditions (Fig. 2A). Image scanning of SDS-PAGE activity gels using AlphaImager software (Alpha Innotech, San Leandro, CA, USA), showed that addition of both amylase and rAbpA to the culture supernatant from the WT resulted in a 1.5- to 3.0fold increase in the Gtf-G and Gtf-C activities by comparison with the single addition of amylase or rAbpA. Increased activities of Gtf-B, Gtf-C and Gtf-D were also observed when both amylase and rAbpA were added (Fig. 2B). Further, SYPRO red staining of SDS-PAGE of amylase precipitates from supernatants showed that amylase in combination with rAbpA precipitated the proteins than when compared with amylase or rAbpA alone (Fig. 2C).

\section{Effects of amylase and rAbpA on sucrase and transferase activities of Gtf-B}

Sucrase activity of the Gtf-B was increased 2- to 2.5-fold (p $<0.001)$, and transferase activity was elevated 4 - to 6-fold $(\mathrm{p}<0.001)$, respectively, in the presence of purified amylase and/or rAbpA (Fig. 3A and 3B). Under identical assay conditions, there was no effect on Gtf-B enzyme activity when BSA alone was added as a control (data not shown). In addition, rAbpA or amylase alone showed little transferase or sucrase activities (Fig. 3). Gtf-B transferase activity in the presence of $\mathrm{rAbpA}$ and/or amylase was significantly greater when compared with Gtf-B alone ( $p \leq$ $0.025)$. Gtf-B sucrase activity was also elevated in presence 


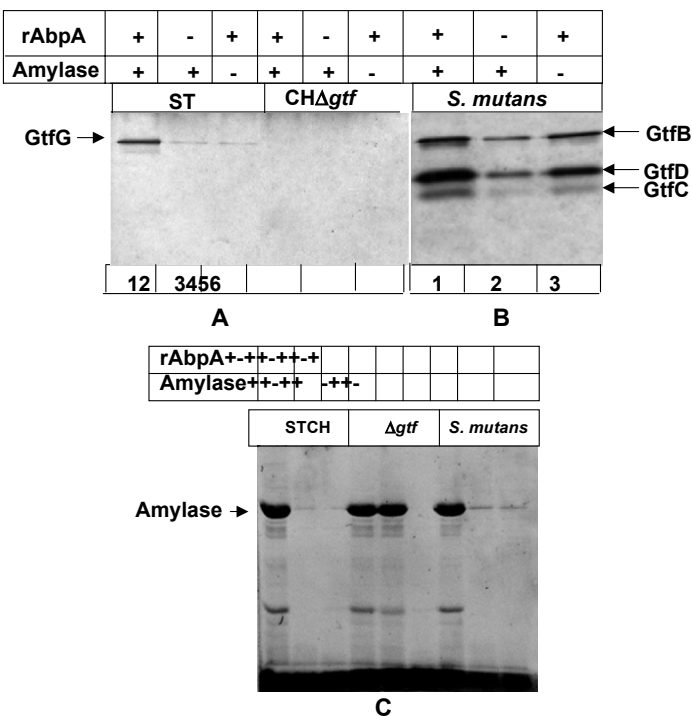

Figure 2

Gtf enzyme activity assay. Overnight culture supernatant of strains in question, containing $3 \mu \mathrm{g}$ total protein were used to precipitate Gtfs. To it, amylase and/or rAbpA was added to a final concentration of $50 \mu \mathrm{g} / \mathrm{ml}$ each. After $2 \mathrm{~h}$ at room temperature, precipitates were collected by centrifugation and resuspended in sample buffer and Gtf activity evaluated on SDS-polyacrylamide gel. Panel A. Lanes: I, 2, and 3, supernatant from $a b p A^{-}$strain (ST); lanes 4,5 , and 6 , supernatant from Gtf-deficient strain. Panel B. Lanes I, 2, and 3, supernatant from S. mutans. Panel C. SDS-PAGE gel of precipitates from supernatants stained with SYPRO red. Lanes I, 2, and 3, supernatants from AbpA-deficient strains; lanes 4, 5, and 6 , supernatants from gtf-negative strains of $S$. gordonii; lanes 7, 8, and 9, supernatants from $S$. mutans.

of rAbpA or rAbpA supplemented with amylase $(p \leq 0.01)$. However, no additive/synergistic effects on sucrase or transferase activities were noted when Gtf-B was incubated together with both rAbpA and amylase.

\section{Binding of rAbpA and amylase with Gtf-B}

The above described results suggested that intermolecular interactions occur between Gtf, AbpA and amylase, and that either amylase or rAbpA alone stimulated activity of Gtf-B, suggesting that these molecules interact with each other. These interactions with Gtf-B were verified using ELISA to measure binding of soluble Gtf-B to immobilized rAbpA or amylase in a dose dependent manner (Fig. 4). Control experiments were also performed demonstrating that neither purified amylase nor rAbpA were able to bind to BSA-coated wells (data not shown). Immobilized rAbpA or amylase also interacted with Gtf-B (Fig. 4) in a manner directly proportional to the amount of immobi-

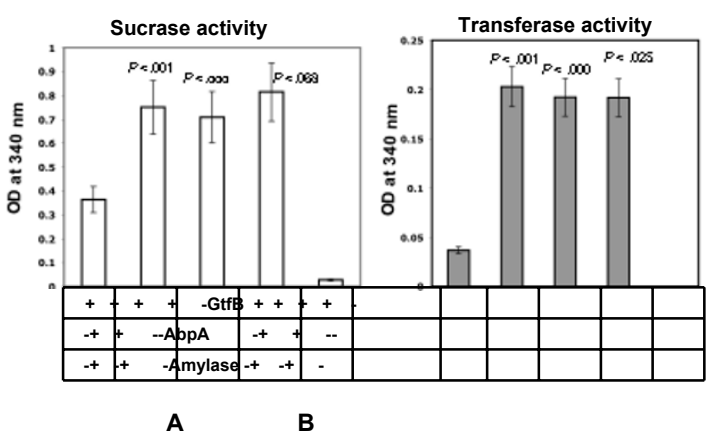

Figure 3

Measurement of sucrase and transferase activities of GtfB. Purified GtfB enzyme was incubated at $37^{\circ} \mathrm{C}$ overnight with sucrose in presence or absence of amylase and/or rAbpA. The amount of glucose and fructose present in the reaction mixtures were measured using the F-kit. Panel $A$ and $B$. Sucrase activity and transferase activity of GtfB in the presence of amylase and/or rAbpA, respectively. For statistical analysis, Gtf-B activities in the presence of amylase and/or rAbpA were compared with Gtf-B alone.

lized proteins, supporting the interaction of rAbpA and amylase with Gtf-B.

\section{Biofilm production by S. gordonii WT and the AbpA- mutant}

In vitro experiments described above indicated that rAbpA interacts with Gtf and increases Gtf enzymatic activity. They suggest a potential role for AbpA as a modulator of $S$. gordonii and S. mutans colonization in the oral cavity. To further explore this, we performed in vitro biofilm experiments to compare the wild-type, AbpA- and Gtf-G negative mutants, in the presence and absence of sucrose and/or saliva (Fig. 5). While the addition of sucrose did not result in differences in final growth between the WT and $\mathrm{AbpA}^{-}$mutant strains as determined by measurement of optical density, sucrose did increase biofilm formation in the AbpA- mutant when compared to the WT (Fig. 5). Surprisingly, biofilm formation by every strain was inhibited in the presence saliva (Fig. 5). Furthermore, the abpA mutant showed a tendency to produce more biofilm growth than the WT in the absence of sucrose.

\section{Discussion}

The results of these studies demonstrate that salivary amylase complexes with Gtf in the presence of AbpA. Addition of exogenous purified amylase to culture supernatants precipitates Gtfs from both wild type and a AbpB- mutant of $S$. gordonii, but not from a AbpA- mutant of $S$. gordonii, or from $S$. mutans (known not to bind amylase or produce any amylase-binding-protein). Both purified rAbpA and amylase increased the level of Gtf enzyme activity. Previ- 


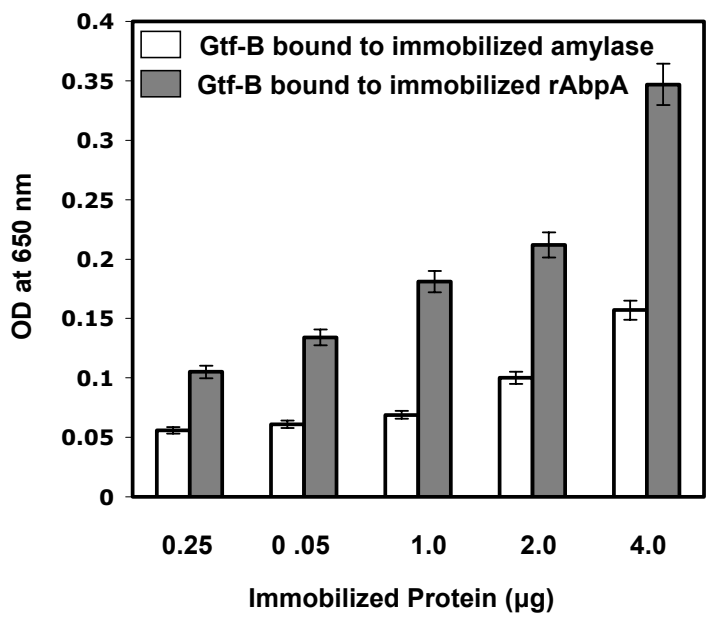

Figure 4

Binding of rAbpA and amylase with GtfB. For coating antigens onto wells of ELISA plate, $4,2,1,0.5$, and $0.25 \mu \mathrm{g}$ of either amylase or rAbpA were used. To each well, I $\mu \mathrm{g}$ of ligand protein (Gtf-B) was added.

ous studies reported that streptococcal Gtfs interact with salivary amylase immobilized on the surface of hydroxyapatite beads, reducing Gtf activity [24]. In the present study, S. mutans Gtf-B in solution interacted with either soluble amylase or with rAbpA with resultant increased enzyme activity. We chose to study Gtf-B since it is strongly associated with cariogenicity of $S$. mutans, it was readily available in pure form, and could potentially interact with AbpA within the multispecies dental plaque biofilm environment. Because the presence of both AbpA and amylase did not synergistically stimulate Gtf activity, we surmise that AbpA and salivary amylase may bind to the same (or nearby) site(s) on Gtf to modulate its enzymatic activity. This is consistent with the known homology of amylase and the Gtf active site regions as previously reported [27].

The abpA-deficient mutant formed quantitatively greater biofilm mass than the WT when grown statically on polystyrene surfaces in both the presence and absence of sucrose, consistent with in vivo findings that the AbpAdeficient mutant strain is a better colonizer of rodent teeth than is the WT strain [18]. The present findings contrast with our previous report that AbpA-deficient strains of $S$. gordonii were less able to form in vitro biofilm than the WT strains [17]. These earlier studies, however, were performed using a flow biofilm model in the presence of $25 \%$ saliva, and in the absence of sucrose. It is also interesting to note that the inclusion of saliva in the present

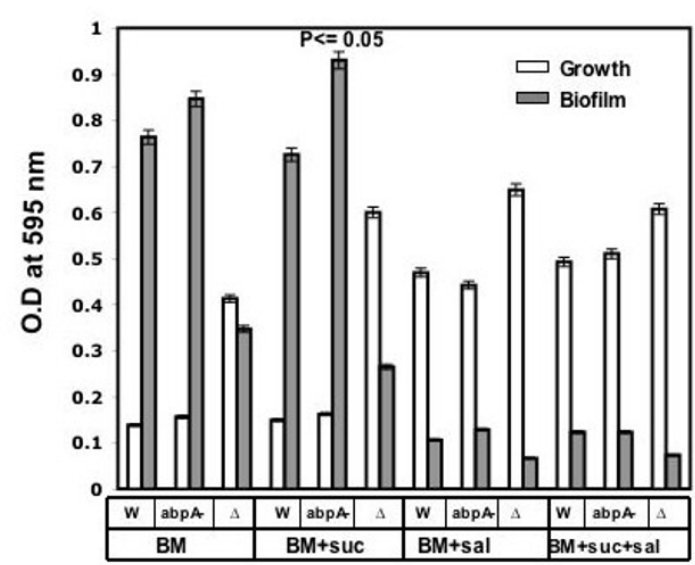

Figure 5

Growth and biofilm formation of wild-type, abp $A$ and $\Delta$ gtf mutants of $S$. gordonii. Bacteria were grown in BM or BM with I\% sucrose and/or $25 \%$ saliva. Growth and biofilm formation were measured under $\mathrm{CO}_{2}$ enriched condition. All assays were performed eight times, and mean values and standard deviations are shown..

model inhibited biofilm formation by all of the bacterial strains tested. This is in contrast to previous studies that show that $S$. gordonii initial adhesion to hydroxyapatite is promoted by saliva [28]. The differences noted in results from the various in vitro models reinforces the limits of in vitro model systems, and the necessity for caution in their interpretation.

Our previous study found that $S$. gordonii strains deficient in AbpA colonized rats fed a sucrose-free starch diet better than their wild-types, and that this differential advantage in colonization was enhanced in rats fed a high sucrose diet [18]. We interpreted these results at that time by suggesting that AbpA may interact with $\mathrm{Gtf}$ to reduce its enzymatic activity, consistent with a previous report [24]. The present results demonstrate that purified AbpA and amylase can interact with Gtf to increase enzymatic activity. It is likely that present in vitro models of biofilm formation are at best a gross simplification of the diverse and complex events occurring in vivo. Thus, a possible explanation for this paradoxical result is that the interaction of amylase and AbpA with Gtf may serve to alter the chemical nature of the resulting glucan products to modulate colonization. Indeed, a previous study found that glucan synthesized by immobilized Gtf-B in the presence of starch hydrolysates was less susceptible to hydrolysis by fungal mutanase than was glucan made by immobilized Gtf-B in the absence of starch hydrolysates [24]. Furthermore, glucan production by Gtf-B associated with streptococci immobilized on saliva-coated hydroxyapatite was also 
enhanced in the presence of starch hydrolysates. Some bacteria displayed higher adhesion activities for the glucan made in the presence of the hydrolysates. The present findings suggest that an amylase-AbpA-Gtf complex may alter the composition of resulting glucans to affect adhesion, biofilm formation and oral bacterial colonization. This possibility deserves further study.

Of course, in vitro experiments performed with purified molecules may not reproduce the in vivo situation. It is possible that additional interactions that occur in vivo influence colonization. Nevertheless, the present results suggest that a protein secreted by S. gordonii (AbpA), along with a host protein (amylase), may together affect the function of $S$. mutans Gtf to influence perhaps $S$. mutans' colonization. This could point to a potential mechanism by which non-mutans streptococci might influence $S$. mutans ecology.

Stimulation of Gtf activity, as seen in the present report, is likely the result of the physical interaction between amylase/rAbpA, with subsequent conformational change in Gtf structure. Taken together, the present observations demonstrate intermolecular interactions between amylase, rAbpA, and Gtf, yielding modulation of Gtf activity in the complex. Studies are now proceeding to examine further the structural basis of the amylase-AbpA-Gtf interaction.

\section{Conclusion}

These studies demonstrate that salivary amylase complexes with Gtf in the presence of AbpA. Addition of exogenous purified amylase to culture supernatants precipitates Gtfs from both wild type and a AbpB- mutant of $S$. gordonii, but not from a AbpA- mutant of $S$. gordonii, or from S. mutans (known not to bind amylase or produce any amylase-binding-protein). Both purified rAbpA and amylase increased the level of Gtf enzyme activity. The results suggest that an extracellular protein network of AbpA-amylase-Gtf may influence the ecology of oral biofilms, likely during initial phases of colonization.

\section{Methods}

\section{Bacterial strains and culture conditions}

S. gordonii strains Challis-S (wild type, a spontaneous streptomycin resistant mutant of strain Challis), and its AbpA-(strain ST) and AbpB-deficient (strain SE) mutants, [16,17], a Gtf-G-deficient mutant $(\mathrm{CH} \Delta g t f)$ [29] and $S$. mutans 10449 S, a spontaneous streptomycin resistant mutant of strain NCTC-10449, were recovered from frozen stocks on tryptic soy blood agar and incubated overnight in a candle jar. Streptococci were routinely cultured in tryptic soy broth (Difco, Detroit, MI. USA) containing $0.5 \%(\mathrm{w} / \mathrm{v})$ yeast extract (TSBY) overnight at $37 \mathrm{C}$.
Escherichia coli was grown in Luria-Bertani broth (LB) with constant shaking at $37^{\circ} \mathrm{C}$ and maintained on $\mathrm{LB}$ agar.

\section{Construction of the AbpA expression system}

The expression vector, pETBlue-1 Blunt (Novagen, Madison, WI. USA), was used to clone and express the abpA of

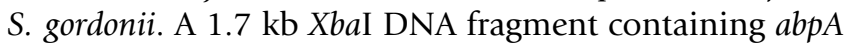
was purified from pCR2kb-7 [15] and then inserted into pETBlue-1 Blunt vector, resulting in plasmid p101-1. The $1.6 \mathrm{~kb}$ EcoRI fragment from p101-1 was purified and digested with ApoI. The resultant 758 bp ApoI fragment was eluted from $2 \%(\mathrm{w} / \mathrm{v})$ agarose gel and cloned into the pETBlue-1 blunt vector, resulting in p102-4, the abpA expression clone. All recombinant plasmids were introduced by chemical transformation into NovaBlue Singles $^{\mathrm{TM}}$ Competent Cells (Novagen), and selected on LB agar supplemented with ampicillin $(100 \mu \mathrm{g} \mathrm{ml})$. The orientations of cloned genes were confirmed by restriction enzyme analysis. Plasmids containing inserts of correct size and orientation were purified using Wizard Plus SV Minipreps DNA Purification System (Promega, Madison, WI, USA), and the fidelity of the cloned region verified by sequencing.

\section{Expression of AbpA in E. coli}

The abpA plasmid p102-4 was transformed into Turner $^{\mathrm{ru}}(\mathrm{DE} 3)$ pLacI Competent Cells (Novagen) which were grown to $1.0 \mathrm{OD}_{600}$ in $250 \mathrm{ml} \mathrm{LB}$ supplemented with ampicillin $\left(50 \mu \mathrm{g} \mathrm{ml}^{-1}\right)$ and $1 \%$ glucose. The cells were induced by the addition of $1 \mathrm{mM}$ isopropyl-D-thiogalactopyranoside (IPTG) for $2 \mathrm{~h}$ at $37^{\circ} \mathrm{C}$ with constant shaking. Cells were harvested by centrifugation at $4000 \times \mathrm{g}$ for 15 min at $4^{\circ} \mathrm{C}$, and the cell pellet ( $\sim 2.3$ g wet weight) was stored frozen at $-20^{\circ} \mathrm{C}$. The induced E. coli cell pellet was suspended in $50 \mathrm{ml}$ of EasyLyse ${ }^{\mathrm{TM}}$ Bacterial Protein extraction solution ( $5 \mathrm{mM}$ Tris- $\mathrm{HCl}(\mathrm{pH} 7.5), 0.5 \mathrm{mM}$ EDTA, $0.5 \%$ Triton X-100, $0.1 \mathrm{mM} \mathrm{MgCl}_{2}$ and $20 \mu \mathrm{l}$ EasyLyse $^{\mathrm{TM}}$ enzyme mix) (Epicentre, Madison, WI, USA). The insoluble cellular debris was removed by centrifugation $(10,000$ $\times \mathrm{g}$ ) at $4^{\circ} \mathrm{C}$ for $10 \mathrm{~min}$ and the soluble supernatant transferred to a clean tube. The total supernatant protein concentrations were estimated using BCA reagent (Bio-Rad, Hercules, CA, USA), and the supernatant containing the rAbpA was stored at $-20^{\circ} \mathrm{C}$.

\section{Purification of rAbpA}

rAbpA was concentrated by anion exchange Macro-prep DEAE methacrylate (Biorad) in a $5 \mathrm{ml}$ column equilibrated with $10 \mathrm{mM}$ Tris buffer, $\mathrm{pH}$ 7.3. Crude supernatant $(10 \mathrm{ml})$ containing $2 \mathrm{mg}$ protein $\mathrm{ml}^{-1}$ of the E. coli extract that included rAbpA was loaded onto the column and eluted by a 0 to $1 \mathrm{M}$ linear $\mathrm{NaCl}$ gradient. Twenty- $5 \mathrm{ml}$ fractions were collected and monitored at $280 \mathrm{~nm}$. All fractions were further analyzed by $12 \%$ SDS-PAGE [30] and stained with either $0.1 \%(\mathrm{w} / \mathrm{v})$ Coomassie bril- 
liant blue R-250 or SYPRO red (Cambrex, Rockland, MI, USA). N-terminal amino acid sequencing was performed to verify the amino acid sequence of rAbpA (data not shown). Purified proteins were lyophilized and stored for further studies.

\section{Western immunoblotting or amylase ligand binding assay} Western blotting [31] was performed by electrotransfer of proteins from SDS-PAGE gels to Immobilon-P membranes (Millipore, Bedford, MA, USA). For the amylase ligand-binding assay, after blocking with $5 \%(\mathrm{w} / \mathrm{v})$ nonfat milk in TBST, membranes were incubated with a solution of purified amylase (Sigma, St. Louis, MO, USA; Cat \# A-1031. A stock solution of $10 \mathrm{mg} / \mathrm{ml}$ was made in deionized water and stored at $-20^{\circ} \mathrm{C}$.) in TBST for $30 \mathrm{~min}$. After washing, the blots were incubated with either polyclonal rabbit anti-AbpA [25] or polyclonal anti-human $\alpha$ amylase (Sigma), washed, and then incubated with goat anti-rabbit IgG conjugated with alkaline phosphatase (Promega). Finally, the blots were developed using the ProtoBlot Western Blot AP system (Promega).

\section{Matrix assisted laser desorption-ionization-time-of-flight analysis}

The pure, lyophilized rAbpA was dissolved in water. Approximately $1 \mathrm{p}$-gram of the protein was mixed with sinapinic acid solution $\left(10 \mathrm{mg} \mathrm{ml}^{-1}\right.$ in $60 \%$ acetonitrile, $0.1 \%$ tri-fluoroacetic acid), spotted onto the sample analysis plate, and dried. The protein was then analyzed by matrix assisted laser desorption-ionization-time-of-flight (MALDI-TOF) mass spectrometry (Bruker Daltonics, Bremen, Germany). Mass spectra were acquired with an accelerating voltage of $19 \mathrm{kV}$ using linear mode. A molecular mass of 18121.024 Da was observed for rAbpA by MALI-TOF (data not shown). The instrument was externally calibrated with carbonic anhydrase and bovine serum albumin.

For mass fingerprinting, about $100 \mu \mathrm{g}$ of the pure lyophilized protein was resuspended in $20 \mu \mathrm{l}$ of $0.25 \mathrm{mg} \mathrm{ml}^{-1}$ sequence grade trypsin (Promega) in water and incubated overnight at $37^{\circ} \mathrm{C}$. Mass spectra were obtained using reflection mode. The monoisotopic masses obtained for the peptides were in the range of 919.523 to 1985.091 . The molecular masses of the digested peptides obtained by MALDI-TOF showed coverage of $47 \%$ and were matched with the peptide masses obtained using Peptidemass software (data not shown). The instrument was calibrated externally with ACTH and angiotensin.

\section{Inhibition of binding of $\left({ }^{125} I\right) \alpha$-amylase by rAbpA to $\mathrm{S}$. gordonii}

These experiments were performed essentially as previously described (Scannapieco, et al. 1989). Briefly, freshly grown $S$. gordonii cells were suspended in PBS containing
$0.01 \%(\mathrm{w} / \mathrm{v})$ lipid-free bovine serum albumin (BSA) to a final concentration of $3 \times 10^{9}$ cells $\mathrm{ml}^{-1}$. Experiments were performed in polypropylene micro-centrifuge tubes precoated with $0.1 \%(\mathrm{w} / \mathrm{v})$ BSA to reduce nonspecific binding of ligand with the tube wall. Reaction mixtures of 0.1 $\mathrm{ml}$, containing 1.1 pmole of (125I) $\alpha$-amylase in PBS, and various amounts of rAbpA were incubated at room temperature for $30 \mathrm{~min}$. To this mixture bacteria suspended in PBS were added to final volume of $0.5 \mathrm{ml}$, mixed gently, incubated for $30 \mathrm{~min}$, and the reaction terminated by centrifugation at room temperature followed by three $1 \mathrm{ml}$ washes with PBS. The amount of radioactivity, reflecting amylase bound to the bacteria, was measured with a gamma counter (Model 5500; Beckman City, CA, USA).

\section{Precipitation of amylase-interactive proteins from S. gordonii culture supernatants}

Supernatants were collected from overnight cultures by centrifugation at $5000 \times \mathrm{g}$ for $10 \mathrm{~min}$ at room temperature and passed through a 0.2 micron filter. Precipitation of proteins was induced by the addition of purified salivary amylase $\left(50 \mu \mathrm{g} \mathrm{ml}^{-1}\right)$ to the supernatant (Li et al., 2002). After incubation at room temperature for $2 \mathrm{~h}$, the precipitate containing amylase and streptococcal proteins was recovered by centrifugation at $5000 \times \mathrm{g}$ for $10 \mathrm{~min}$, resuspended in sample buffer (0.06 M Tris-HCl, pH 6.8, 10\% $(\mathrm{v} / \mathrm{v})$ glycerol, $2 \%(\mathrm{w} / \mathrm{v})$ SDS, 0.05\% (v/v) 2- $\beta$-mercaptoethanol and $0.00125 \%$ bromophenol blue, and boiled for $3 \mathrm{~min}$. Subsequently, the precipitate components were resolved on $12 \%$ SDS-PAGE, stained with SYPRO RED in $7.5 \%(\mathrm{v} / \mathrm{v})$ acetic acid, and photographed under UV light.

\section{Glucosyltranferase activity assay}

Gtf activity was evaluated by both qualitative and quantitative assays. For qualitative assays, activity was determined in polyacrylamide gels as previously described [32]. Briefly, cell free supernatants were run on SDS-PAGE followed by overnight incubation of gel in 3\% sucrose. The glucan bands synthesized by the GTF were visualized by staining with periodic acid and pararosanaline.

The component sucrase and transferase activities of Gtf-B were differentially quantified as previously described [33,34]. Briefly, $0.6 \mu \mathrm{g}$ of soluble Gtf-B (kindly provided by Dr. Ann Vacca-Smith, University of Rochester, NY, USA) in $2 \mu \mathrm{l}$ of $0.2 \mathrm{M}$ sodium phosphate buffer ( $\mathrm{pH} 6.0$ ), was incubated in the presence or absence of various amounts of soluble rAbpA ( $2 \mu \mathrm{l})$ and/or amylase $(2 \mu \mathrm{l}$ in buffer) at room temperature for $5 \mathrm{~min}$. To this, $50 \mu \mathrm{l}$ of buffer and $40 \mu \mathrm{l}$ of $1 \mathrm{M}$ sucrose in water were added to a final volume of $100 \mu \mathrm{l}$ and the reaction mixture was incubated overnight at $37^{\circ} \mathrm{C}$. The amounts of free glucose and fructose in the reaction mixture were measured by an enzymatic-redox reaction train using hexokinase, glucose6-phosphate dehydrogenase, 6-phosphoglucose isomer- 
ase, and NADP + (F-Kit, R-Biopharm, Mannheim, Germany). The amount of resulting fructose in the reaction mixture represents sucrase activity; the difference between the amounts of free glucose and free fructose in the reaction mixture corresponds to the amount of glucosyl residues transferred to glucan, and thus the transferase activity [35]. Means ( \pm S.E.) were used to describe the enzyme activities.

Interaction of rAbpA and amylase with Gtf-B of S. mutans ELISA was used to verify the interaction of rAbpA and amylase with Gtf-B. Two-fold dilutions of Gtf-B or rAbpA were coated onto wells of ELISA plates. The plates were washed and blocked as per manufacturers instructions (Kirkegaard and Perry, Gaithersburg, MD). To each well, 1 $\mu \mathrm{g}$ of purified amylase, Gtf-B or rAbpA was added and incubated at room temperature for $2 \mathrm{hr}$. After washing, the samples were probed with polyclonal anti-Gtf-B (kindly provided by Dr. Ann Vacca-Smith), anti-AbpA (25), or anti-amylase antibodies, as appropriate. The plates were then incubated, washed, and probed with the secondary antibody provided in the ELISA kit. The plates were developed using the kit substrate according to the manufacturer's instructions. Following color development, which was proportional to the amount of target protein interacting with the protein bound to the plate, the OD of the solution was read at $630 \mathrm{~nm}$ in a plate reader.

\section{Biofilm assay}

Biofilm experiments were performed in round-bottomed polystyrene microtiter plates (Nalge Nunc International, Rochester, New York, USA). Plates containing $200 \mu \mathrm{l}$ of biofilm media (BM) [36] in the presence or absence of $1 \%$ sucrose and/or $25 \%$ filter sterilized saliva per well were inoculated with either WT or mutant strains of $S$. gordonii $\left(5 \times 10^{7} \mathrm{CFU}\right.$ per well) from an overnight culture grown in TSBY. After $20 \mathrm{~h}$ of incubation at $37^{\circ} \mathrm{C}$, resultant bacterial growth in each well was quantified by measuring the absorbance at $595 \mathrm{~nm}$. The wells were then washed with PBS and the biofilm that formed on the walls of the wells was fixed for $5 \mathrm{~min}$ by adding $200 \mu \mathrm{l}$ of methanol at room temperature. Following air drying, $100 \mu \mathrm{l}$ of $0.1 \%$ crystal violet $(\mathrm{CV})$ solution was added to each well. After $5 \mathrm{~min}$, the wells were rinsed three times with $200 \mu \mathrm{l}$ of distilled water and air-dried. To each well, $200 \mathrm{ml}$ of $95 \%$ ethanol was added and placed in a rocker for $15 \mathrm{~min}$. The CV eluted from the biofilm was then quantified by measuring the absorbance at $630 \mathrm{~nm}$ using an ELISA plate reader.

\section{Statistical analysis}

Statistical analyses were conducted using SPSS software, version 11. Analyses of the enzyme activity were done using the two-sided t-test. Differences were considered significant when a P value of 0.05 was obtained.

\section{Abbreviations}

AbpA, amylase-binding-protein A; AbpB, amylase-binding-protein $\mathrm{B}$; rAbpA, recombinant amylase-binding-protein A; BM; biofilm medium; BSA, bovine serum albumin; CV crystal violet; ELISA, enzyme-linked immunosorbent assay; Gtf, glucosyltransferase; kDa, kilo Dalton; MALDITOF, matrix-assisted laser desorption-ionization-time-offlight; TBST, tris buffered saline with Tween 20; WT, wildtype.

\section{Authors' contributions}

BC contributed to the design of all experiments, performed cloning, recombinant protein expression, characterization of recombinant protein, precipitation and analyses of protein complex, Western blotting, sequence analysis, MALDI-TOF, glucosyl transferase activity assay, biofilm experiments, participated in the analysis and interpretation of data, co-drafted and co-wrote the manuscript. JR purified recombinant protein. MMV assisted with writing the manuscript and supplied the gtf-negative strain. JMT participated in the interpretation of data, and contributed to writing the manuscript. FAS conceived of the project, advised in the design of experiments, codrafted and co-wrote the manuscript. All authors read and approved the final manuscript.

\section{Acknowledgements}

We thank Dr. Molakala Reddy and Mr. Paul Bronson (Department of Oral Biology, University at Buffalo, NY, USA) for their assistance in protein purification and Dr. Norma Greenfield (UMDNJ-Robert Wood Johnson Medical School, New Jersey, USA) for analysis of CD spectra data. We also thank Dr. Ann Vacca-Smith (University of Rochester, USA) for providing purified S. mutans Gtfs and rabbit anti-GTF antibody. We appreciate the helpful discussions with Dr. Oelisoa M. Andriankaja (University at Buffalo, USA) regarding statistical analyses. This research was supported by Grants DE07034 and DE09838 from the National Institutes of Health, USA.

\section{References}

I. Scannapieco FA: Saliva-bacterium interactions in oral microbial ecology. Crit Rev Oral Biol Med 1994, 5:203-248.

2. Douglas CWI: Bacterial-protein interactions in the oral cavity. Adv Dent Res 1994, 8:254-262.

3. Rudney JD: Saliva and dental plaque. Adv Dent Res 2000, I 4:29-39.

4. Scannapieco FA, Torres G, Levine MJ: Salivary $\alpha$-amylase: role in dental plaque and caries formation. Crit Rev Oral Biol Med I993, 4:301-307.

5. Tatevossian A, Newbrun E: Enzymic activities in the aqueous phase of human dental plaque. Arch Oral Biol 1979, 24:657-662.

6. Fiehn N-E, Moe $D: \alpha$-Amylase activity in supragingival dental plaque in humans. Scand J Dent Res 1983, 91:365-370.

7. Yao Y, Grogan J, Zehnder M, Lendenmann U, Nam B, Wu Z, Costello CE, Oppenheim FG: Compositional analysis of human acquired enamel pellicle by mass spectrometry. Arch Oral Biol 200I, 46:293-303.

8. Rosan B, Lamont RJ: Dental plaque formation. Microbes Infect 2000, 2(13): I599-1607.

9. Tanzer JM, Livingston J, Thompson AM: The microbiology of primary dental caries in humans. J Dent Educ 200I, 65(10): 1028-1037.

10. Scannapieco FA, Bergey EJ, Reddy MS, Levine MJ: Characterization of salivary $\alpha$-amylase binding to Streptococcus sanguis. Infect Immun 1989, 57:2853-2863. 
II. Douglas CWI: Characterization of the $\alpha$-amylase receptor of Streptococcus gordonii NCTC 7868. J Dent Res 1990, 69:1746-1752.

12. Kilian M, Nyvad B: Ability to bind salivary alpha-amylase discriminates certain viridans group streptococcal species. J Clin Microbiol I 990, 28(I I):2576-2577.

13. Gwynn JP, Douglas CW: Comparison of amylase-binding proteins in oral streptococci. FEMS Microbiol Lett 1994, 124(3):373-379.

14. Scannapieco FA, Solomon L, Wadenya RO: Emergence in human dental plaque and host distribution of amylase-binding streptococci. J Dental Res 1994, 73(10): 1627-1635.

15. Rogers JD, Haase EM, Brown AE, Douglas CWI, Gwynn JP, Scannapieco FA: Identification and analysis of a gene $(a b p A)$ encoding a major amylase-binding protein in Streptococcus gordonii. Microbiology 1998, 144:1223-1233.

16. Li L, Tanzer JM, Scannapieco FA: Identification and analysis of the amylase-binding protein $B(A b p B)$ and gene (abpB) from Streptococcus gordonii. FEMS Microbiol Lett 2002, 212(2): I5I-I57.

17. Rogers JD, Palmer RJ Jr, Kolenbrander PE, Scannapieco FA: Role of Streptococcus gordonii amylase-binding protein $A$ in adhesion to hydroxyapatite, starch metabolism, and biofilm formation. Infect Immun 200 I, 69( I I ):7046-7056.

18. Tanzer JM, Grant L, Thompson A, Li L, Rogers JD, Haase EM, Scannapieco FA: Amylase-binding proteins A (AbpA) and B (AbpB) differentially affect colonization of rats' teeth by Streptococcus gordonii. Microbiology 2003, I49:2653-2660.

19. Tanzer JM, Freedman ML, Fitzgerald RJ, Larson RH: Diminished virulence of glucan synthesis-defective mutants of Streptococcus mutans. Infect Immun 1974, IO(I):197-203.

20. Banas JA, Vickerman MM: Glucan-binding proteins of the oral streptococci. Crit Rev Oral Biol Med 2003, I 4(2):89-99.

21. Vickerman MM, Sulavik MC, Nowak JD, Gardner NM, Jones GW, Clewell DB: Nucleotide sequence analysis of the Streptococcus gordonii glucosyltransferase gene, gtfG. DNA Seq 1997, 7(2):83-95.

22. Kuramitsu $\mathrm{H}$ : Virulence factors of mutans streptococci: role of molecular genetics. Crit Rev Oral Biol Med 1993, 4:159-176.

23. Mooser G, Wong C: Isolation of a glucan-binding domain of glucosyltransferase (1,6-alpha-glucan synthase) from Streptococcus sobrinus. Infect Immun 1988, 56(4):880-884.

24. Vacca-Smith AM, Venkitaraman AR, Quivey RG Jr, Bowen WH: Interactions of streptococcal glucosyltransferases with alpha-amylase and starch on the surface of saliva-coated hydroxyapatite. Arch Oral Biol 1996, 4I(3):291-298.

25. Scannapieco FA, Haraszthy GG, Cho MI, Levine MJ: Characterization of an amylase-binding component from Streptococcus gordonii G9B. Infect Immun 1992, 60:4726-4733.

26. Douglas $\mathrm{CW}$ : The binding of human salivary alpha-amylase by oral strains of streptococcal bacteria. Arch Oral Biol 1983, 28(7):567-573.

27. Mooser G, Hefta SA, Paxton RJ, Shively JE, Lee TD: Isolation and sequence of an active-site peptide containing a catalytic aspartic acid from two Streptococcus sobrinus alpha-glucosyltransferases. J Biol Chem I991, 266( I 4):8916-8922.

28. Gibbons RJ, Hay DI, Schlesinger DH: Dilineation of a segment of adsorbed salivary acidic prolijne-rich proteins which promotes adhesion of Streptococcus gordonii to apatitic surfaces. 1991, 59:2948-2954.

29. Banas JA, Fountain TL, Mazurkiewicz JE, Sun K, Vickerman MM: Expression of the Streptococcus mutans glucan-binding protein-A within the heterologous host Streptococcus gordonii alters biofilm architecture. FEMS Microb Lett 2006. Accepted for publication

30. Laemmli UK: Cleavage of structural proteins during assembly of the head of bacteriophage T4. Nature (London) 1970 277(5259):680-685.

31. Burnette WN: "Western Blotting". Electrophoretic transfer of proteins from sodium dodecyl sulphate-polyacrylamide gels to unmodified nitrocellulose and radiographic detection with antibody and radioiodinated protein A. Anal Biochem I 98I, I I 2: 195-203.

32. Vickerman MM, Minick PE: Genetic Analysis of the rgg-gtfG Junctional Region and Its Role in Streptococcus gordonii Glucosyltransferase Activity. Infect Immun 2002, 70(4): I703-17|4.
33. Eto A, Saido TC, Fukushima K, Tomioka S, Imai S, Nisizawa T, Hanada $\mathrm{N}$ : Inhibitory effect of a self-derived peptide on glucosyltransferase of Streptococcus mutans. Possible novel anticaries measures. J Biol Chem 1999, 274(22): I5797-| 5802.

34. Shiroza T, Shinozaki-Kuwahara N, Hayakawa M, Shibata Y, Hashizume T, Fukushima K, Udaka S, Abiko Y: Production of a single-chain variable fraction capable of inhibiting the Streptococcus mutans glucosyltransferase in Bacillus brevis: construction of a chimeric shuttle plasmid secreting its gene product. Biochim Biophys Acta 2003, 1626(I-3):57-64.

35. Walker JE, Saraste M, Runswick MJ, Gay NJ: Distantly related sequneces in the a and $\beta$-subunits of ATP synthase, myosin, kinases and other ATP-requiring enzymes and a common nucleotide binding fold. $E M B O \mathrm{~J}$ I 982 , I:945-95I.

36. Loo CY, Corliss DA, Ganeshkumar N: Streptococcus gordonii biofilm formation: identification of genes that code for biofilm phenotypes. J Bacteriol 2000, I82(5): I374-I 382.
Publish with Bio Med Central and every scientist can read your work free of charge

"BioMed Central will be the most significant development for disseminating the results of biomedical research in our lifetime. "

Sir Paul Nurse, Cancer Research UK

Your research papers will be:

- available free of charge to the entire biomedical community

- peer reviewed and published immediately upon acceptance

- cited in PubMed and archived on PubMed Central

- yours - you keep the copyright 